\title{
Optimization of Culture Conditions for Biomass Production of Ganoderma lucidum
}

\author{
Pooja Shah" and H.A. Modi \\ Department of Life Science, Gujarat University, Ahmedabad-380009, Gujarat, India \\ *Corresponding author
}

\section{A B S T R A C T}

\section{Keywords}

Ganoderma lucidum,

Mycelial biomass,

One factor at a time,

Optimization

Article Info

Accepted:

17 January 2018

Available Online:

10 February 2018
The study aimed at optimizing the mycelial biomass production of G. lucidum by submerged fermentation. Conventional one factor at a time was used as an initial screening process, i.e., one factor was varied, while keeping all the others constant. Different factors like $\mathrm{pH}$, temperature, carbon source, nitrogen source and inoculum size were selected for the optimization process. The optimum $\mathrm{pH}$ and temperature of the medium was found to be 5 and $30^{\circ} \mathrm{C}$ respectively. Different carbon and nitrogen sources were screened for optimum mycelial biomass production. Glucose at a concentration of $1.5 \% \mathrm{w} / \mathrm{v}$ and yeast extract at a concentration of $0.25 \% \mathrm{w} / \mathrm{v}$ was found to be the most effective for the mycelial biomass production. Further, an inoculum size of $6 \%(\mathrm{v} / \mathrm{v})$ was found to be the best for mycelial biomass production of $G$. lucidum. The maximum dry mycelial biomass obtained after combining these optimum conditions was found to be $368 \pm 3.71 \mathrm{mg} / 100 \mathrm{~mL}$.

\section{Introduction}

Species of the genus Ganoderma have been reported to occur throughout the world and over 250 species of this mushroom are known (Sheena et al., 2005).One important species of this genus is Ganoderma lucidum, which has been used for over 2000 years in Japan, China and Korea as a traditional medicine due to its properties associated with health and healing. The main functional components of $\mathrm{G}$. lucidum include polysaccharides, proteins, peptides, amino acids, triterpenes, steroids, alkaloids, nucleotides, lactones, and fatty acids (Sood et al., 2013). Recent studies have revealed that the most important active constituents of G. lucidum are polysaccharides and ganoderic acids (Xu et al., 2008). However, their contents vary significantly from strain to strain.It has been shown that this fungus is useful in treating and preventing high blood pressure, hyperglycemia, hepatitis, chronic bronchitis, asthma, heart diseases, cancer and HIV, as well as its great effect on slowing down cell senescence and its antioxidant content (Zárate-Chaves et al., 2013).

Due to such large number of health-promoting effects of the mushroom, it is widely cultivated and has a high demand. But, before it can be used in various health sectors, it is necessary to establish the composition of the culture medium for production of the biomass 
on a large scale. Since the growth of mycelia has been found to be related with various environmental factors like $\mathrm{pH}$ and Temperature and the nutrients that are available to it, an attempt was made in studying the different factors $(\mathrm{pH}$, temperature, carbon source, nitrogen source, inoculum size) that affect the growth of mycelial biomass of the mushroom. The following study aimed at optimizing the mycelial biomass production of G. lucidum by submerged fermentation. Submerged cultures have the potential for higher mycelial production in a compact space and in shorter time with fewer chances for contamination, hence submerged medium was used. For optimizing the cultural conditions for maximum biomass production of G. lucidum, one factor at a time method was used, i.e., one factor was varied, while keeping all the others constant.

\section{Materials and Methods}

\section{Microorganism}

Mycelia of Ganoderma lucidum (MTCC 1039) was procured from The Microbial Type Culture Collection and Gene Bank (MTCC), Institute of Microbial Technology (IMTECH), Chandigarh, India. It was maintained in potato dextrose agar (PDA) plates at $25^{\circ} \mathrm{C}$ for 9 days and were periodically transferred onto a new PDA medium. The strain was maintained at $4^{\circ} \mathrm{Cand}$ the growth was observed.

\section{Media and inoculum preparation}

The seed culture media consisted of $1.5 \mathrm{~g}$ glucose, $0.2 \mathrm{~g}$ yeast powder, $0.1 \mathrm{~g} \mathrm{KH}_{2} \mathrm{PO}_{4}$, $0.1 \mathrm{~g} \mathrm{~K}_{2} \mathrm{HPO}_{4}, 0.15 \mathrm{~g} \mathrm{MgSO}_{4} .7 \mathrm{H}_{2} \mathrm{O}$, and $0.25 \mathrm{~g}$ peptone dissolved in $100 \mathrm{~mL}$ double distilled water (DDW).Three pieces of $5 \mathrm{~mm}$ diameter of actively growing culture from agar plate (9 days old) was transferred with the help of a $5 \mathrm{~mm}$ cork borer into $250 \mathrm{~mL}$ Erlenmeyer flasks containing $100 \mathrm{~mL}$ of the seed culture at $25^{\circ} \mathrm{Cin}$ an orbital shaker at $150 \mathrm{rpm}$ for 10 days (Shah and Modi, 2015).

\section{Optimization by one factor at a time}

\section{Selection of pH}

To determine the optimum $\mathrm{pH}$, six Erlenmeyer $(250 \mathrm{~mL})$ flasks were taken and maintained at an initial $\mathrm{pH} 4.5,5,5.5,6,6.5,7$. The medium used for this study was similar to the seed culture medium. $5 \%$ of inoculum was used from the seed culture flask and transferred into the flasks containing $100 \mathrm{~mL}$ media. The six flasks were incubated at $25^{\circ} \mathrm{C}$ at $150 \mathrm{rpm}$ for 10 days.

\section{Selection of temperature}

For determination of optimum temperature, six Erlenmeyer $(250 \mathrm{~mL})$ flasks were taken and were incubated at $5^{\circ} \mathrm{C}, 15^{\circ} \mathrm{C}, 20^{\circ} \mathrm{C}, 25^{\circ} \mathrm{C}$, $30^{\circ} \mathrm{C}$ and $35^{\circ} \mathrm{C}$. 5\% of inoculum was transferred from seed culture flask containing $100 \mathrm{~mL}$ of media. The flasks were incubated at $150 \mathrm{rpm}$ for 10 days.

\section{Selection of carbon source}

To determine the optimum carbon source six different carbon sources were selected, i.e. glucose, fructose, maltose, lactose, xylose and sucrose at a concentration of $1.5 \%(\mathrm{w} / \mathrm{v}) .250$ $\mathrm{mL}$ Erlenmeyer flasks containing $100 \mathrm{~mL}$ of the following media: $0.2 \%$ yeast powder, $0.1 \% \quad \mathrm{KH}_{2} \mathrm{PO}_{4}, \quad 0.1 \% \quad \mathrm{~K}_{2} \mathrm{HPO}_{4}, \quad 0.15 \%$ $\mathrm{MgSO}_{4} .7 \mathrm{H}_{2} \mathrm{O}, 0.25 \%$ peptone and $1.5 \%$ of the respective carbon sources were added in individual flasks.

Each flask was inoculated with $5 \%(\mathrm{v} / \mathrm{v})$ of seed culture at $150 \mathrm{rpm}, 25^{\circ} \mathrm{C}$ for 10 days. The optimized carbon source was further studied for its optimum concentration from a range of $0.5-3.0 \%(\mathrm{w} / \mathrm{v})$. 


\section{Selection of nitrogen source}

To determine the optimum nitrogen source six different nitrogen sources were selected i.e. yeast extract, peptone, ammonium sulphate, ammonium chloride, sodium nitrate, potassium nitrate at a concentration of $0.25 \%$ (w/v) each.

Each $250 \mathrm{~mL}$ Erlenmeyer flask contained 100 $\mathrm{mL}$ of the following media: $1.5 \%$ glucose, $0.1 \% \quad \mathrm{KH}_{2} \mathrm{PO}_{4}, \quad 0.1 \% \quad \mathrm{~K}_{2} \mathrm{HPO}_{4}, \quad 0.15 \%$ $\mathrm{MgSO}_{4} .7 \mathrm{H}_{2} \mathrm{O}$ and $0.25 \%$ of the respective nitrogen sources in individual flasks.

Each flask was inoculated with $5 \%(\mathrm{v} / \mathrm{v})$ of the seed culture and maintained at $150 \mathrm{rpm}, 25^{\circ} \mathrm{C}$ for 10 days. The optimized nitrogen source was further studied for its optimum concentration from a range of $0.05-0.3 \%$ $(\mathrm{w} / \mathrm{v})$.

\section{Selection of inoculum size}

Foroptimum inoculum volume determination, five Erlenmeyer $(250 \mathrm{~mL})$ flasks were taken having media similar to that of seed culture media. Different inoculum sizes of 3\%, $4 \%$, $5 \%, 6 \%$ and $7 \%(\mathrm{v} / \mathrm{v})$ were taken.

The inoculum was transferred from the seed culture media into the Erlenmeyer flasks containing $100 \mathrm{~mL}$ of the media and was maintained at $25^{\circ} \mathrm{C}$ at $150 \mathrm{rpm}$ for 10 days.

\section{Harvesting}

After the incubation period, the culture media containing the mycelia were decanted and each medium was separately filtered using Whatman \#4 filter paper until a clear filtrate was obtained. The mycelia were washed with DDW twice and were oven dried overnight at $50^{\circ} \mathrm{C}$ until a constant dry weight was obtained (Feng et al., 2010). The dry mycelia were weighed in $\mathrm{mg} / 100 \mathrm{~mL}$ and recorded.

\section{Statistical analysis}

All experiments were performed in triplicates to ensure reproducibility. All the data are expressed as mean $\pm \mathrm{SD}$ (Standard deviation) of three replicates.

\section{Results and Discussion}

\section{Effect of initial $\mathrm{pH}$ and temperature}

$\mathrm{pH}$ and temperature are important environmental factors that control the growth of fungi. In this study, G lucidum was found to grow best in acidic environments ( $\mathrm{pH}$ 4.5-5.5). From Figure 1a, it is clear that the maximum weight of dry mycelial biomass of $291 \pm 3.18$ $\mathrm{mg} / 100 \mathrm{~mL}$ was observed at $\mathrm{pH} 5$. Moderate mycelial biomass of $262 \pm 3.67 \mathrm{mg} / 100 \mathrm{~mL}$ was observed at $\mathrm{pH} 4.5$. The initial $\mathrm{pH}$ of the fermentation broth, is an important parameter for mycelial growth as it may affect fungal cell membrane function, cell morphology and structure and the utilization of various nutritional requirements. It has been reported that acidic $\mathrm{pH}$ has been more suitable for mycelial growth and production of metabolites for many kinds of ascomycetes and basidiomycetes (Shih et al., 2007). The yield of G. lucidum mycelium was found to be highest at an acidic $\mathrm{pH}$ (6.5) according to a study done by (Chang et al., 2006). The growth of mycelium of other basidiomycetes like L. tuberregium and Grifolafrondosa was also found to be maximum at an acidic $\mathrm{pH}$ of 6.5 and 5.5 respectively (Manjunathan and Kaviyarasan, 2011; Lee et al., 2004). The best vegetative growth of the mushroom $P$. atroumbonata was also found to be at an acidic pH of 6.5 (Jonathan and Fasidi, 2003). Studies done on Volvariella speciosa (Fasola et al., 2007) showed that the best growth occurred at $\mathrm{pH} 6$ which is again an acidic $\mathrm{pH}$.

For determination of optimum temperature, a range of $5-35^{\circ} \mathrm{C}$ was selected. The maximum 
dry mycelial biomass of $276 \pm 2.47 \mathrm{mg} / 100 \mathrm{~mL}$ was observed at $30^{\circ} \mathrm{C}$. At $25^{\circ} \mathrm{C}$, similar results as that for $30^{\circ} \mathrm{C}$ were seen with the mycelial biomass weighing $251 \pm 2.98 \mathrm{mg} / 100 \mathrm{~mL}$. Thus, the results indicated that the optimum temperature for maximal biomass production was $30^{\circ} \mathrm{C}$ (Fig. 1b). The optimum temperature obtained was similar to other submerged culture studies done on Basidiomycetes (Manjunathan and Kaviyarasan, 2011; Lee et al., 2004; Fasola et al., 2007; Teoh and Don, 2012; Hamedi, et al., 2007; Xiao et al., 2006).

\section{Effect of carbon and nitrogen source}

From (Fig. 2a), it's clear that the medium containing glucose was significant in yielding the highest mycelial growth $(289 \pm 1.09$ $\mathrm{mg} / 100 \mathrm{~mL}$ ) when compared to the other carbon sources. Maltose also gave a relatively good yield of $271 \pm 3.76 \mathrm{mg} / 100 \mathrm{~mL}$ of dry mycelial biomass followed by fructose (210 $\pm 1.37 \mathrm{mg} / 100 \mathrm{~mL})$.

In a study done by (Suberu et al., 2013) on the growth of G. lucidum mycelia, maltose gave the highest yield followed by glucose. Many studies done on other basidiomycetes like $G$. frondosa and Psathyerella atroumbonata, showed glucose to be the most effective carbon source for mycelial biomass production (Lee et al., 2004; Jonathan and Fasidi, 2003). Figure $2 \mathrm{~b}$ shows that $1.5 \% \mathrm{w} / \mathrm{v}$ was found to be the optimum concentration of glucose for highest biomass production $(307 \pm 3.97 \mathrm{mg} / 100 \mathrm{~mL})$ of $G$. lucidum, followed by $2 \% \mathrm{w} / \mathrm{v}(257 \pm 1.97 \mathrm{mg} / 100 \mathrm{~mL})$. These results for the effect of concentration of glucose on the growth of mycelia were different from those obtained by (Yuan et al., 2012), on a novel strain of Ganoderma lucidum, CAU5501 where a high concentration of $6 \% \mathrm{w} / \mathrm{v}$ was found to be the optimum concentration of glucose. $G$. frondosa (Lee et al., 2004) gave maximum yield at a concentration of $3 \% \mathrm{w} / \mathrm{v}$ of glucose which was again high as compared to the results obtained in the present study. The preference of glucose over other carbon compounds may be due to the ease with which this sugar is metabolised to produce cellular energy (Jonathan and Fasidi, 2001). Maltose, the second-best carbohydrate can be transformed to glucose during metabolism.

Figure $3 \mathrm{a}$, shows that among the six nitrogen sources that were tested, yeast extract was found to be most suitable for the growth of mycelial biomass $(279 \pm 2.18 \mathrm{mg} / \mathrm{mL})$, followed by peptone, which yielded a dry mycelial biomass of $259 \pm 3.33 \mathrm{mg} / 100 \mathrm{~mL}$. Hence, organic nitrogen sources were found to be better than the inorganic nitrogen sources, which are in accordance to the study done previously on G. lucidum (Suberu et al., 2013).

Other authors working on basidiomycetes like Lentinus tuberregium, G. frondosa, Agaricus blazei and Psathyerella atroumbonata also found yeast extract to be the best nitrogen source for the growth of mycelial biomass (Manjunathan and Kaviyarasan, 2011; Lee et al., 2004; Hamedi et al., 2007; Jonathan and Fasidi, 2001). Yeast extract being a vitamin B complex source, supports effective cell development. Most Basidiomycetes prefer complex organic sources, because certain essential amino acids may not be synthesized from inorganic nitrogen sources in submerged culture of higher fungi (Papaspyridi et al., 2010).

Different concentrations of yeast extract were used to get a better yield of biomass. Yeast extract at a concentration of $0.25 \% \mathrm{w} / \mathrm{v}$ was found to be the most effective for the mycelial biomass production $(294 \pm 1.53 \mathrm{mg} / 100 \mathrm{~mL})$. A concentration of $0.3 \% \mathrm{w} / \mathrm{v}$ was also found to be effective in giving a decent yield of $271 \pm 2.42 \mathrm{mg} / 100 \mathrm{~mL}$ (Fig. 3b). 
Fig.1 Effect of (a) pH and (b)Temperture on mycelial biomass of G. lucidum. All experimental data are mean \pm S.D. of triplicates

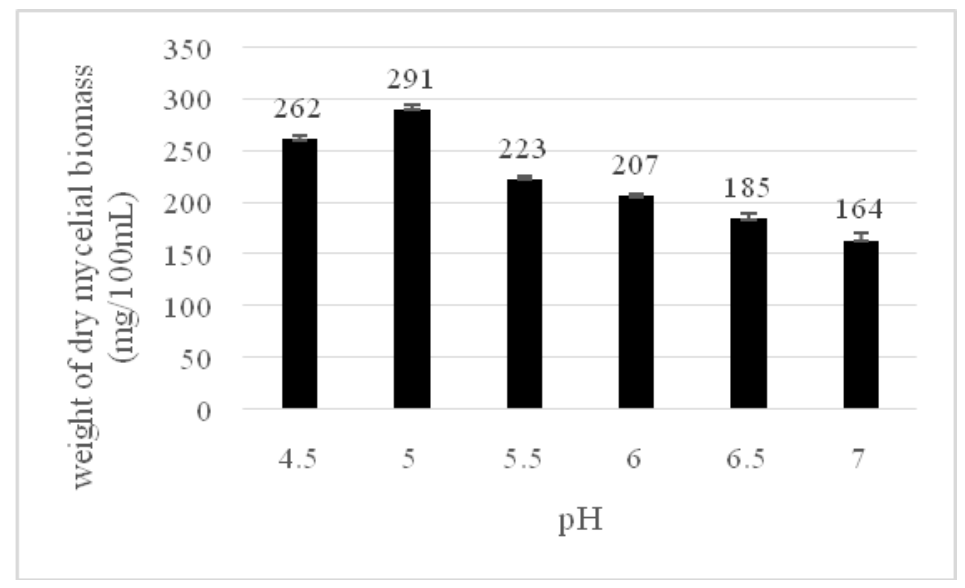

Fig.1 (a)

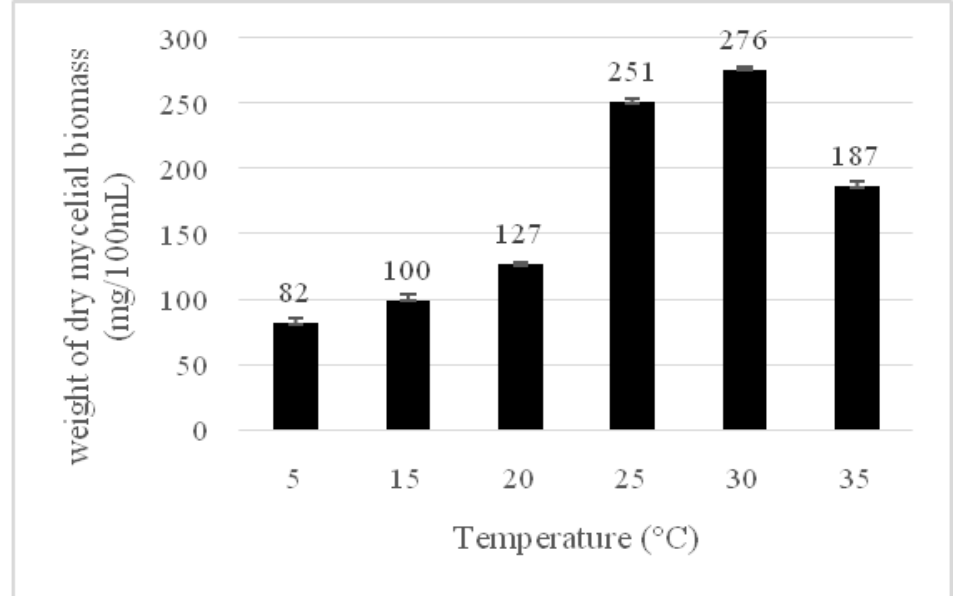

Fig.1 (b)

Fig.2 Effect of (a) different carbon sources and (b) different concentrations of glucose on biomass production of G. lucidum. All experimental data are mean \pm S.D. of triplicates

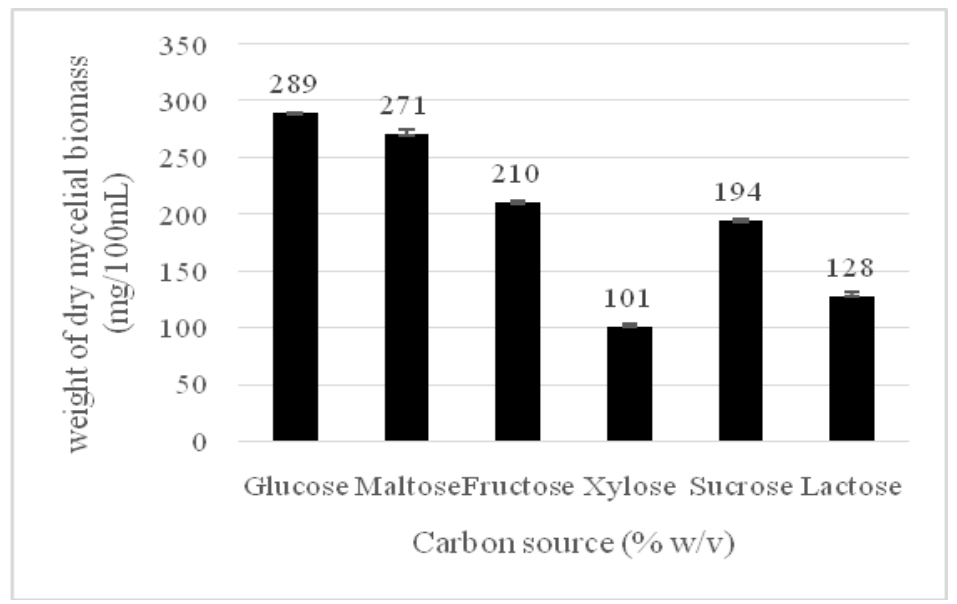

Fig.2 (a) 


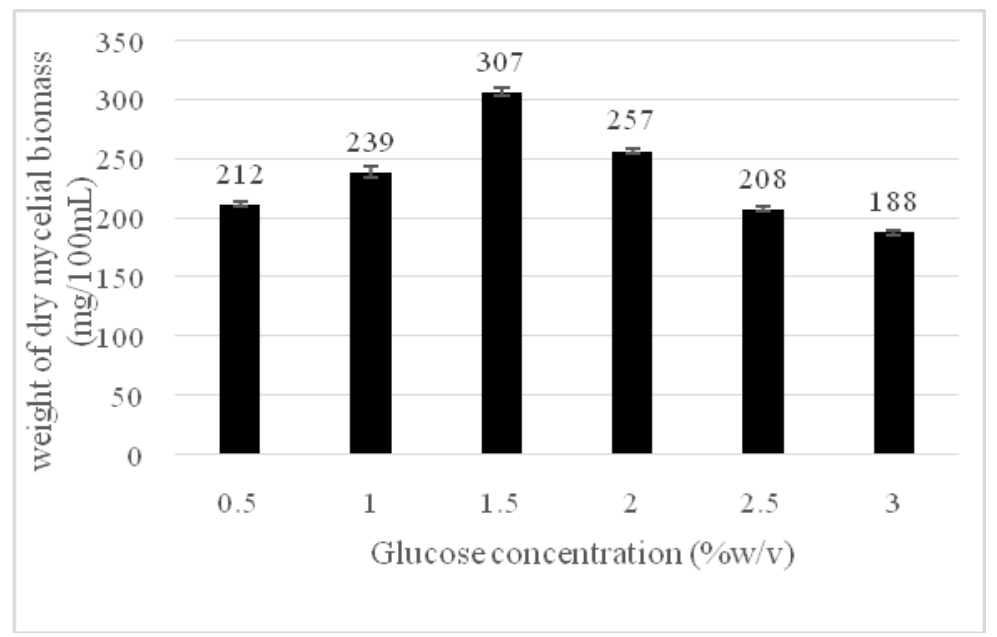

Fig.2 (b)

Fig.3 Effect of (a) different nitrogen sources and (b) different concentrations of yeast extract on biomass production of $G$. lucidum. All experimental data are mean \pm S.D. of triplicates

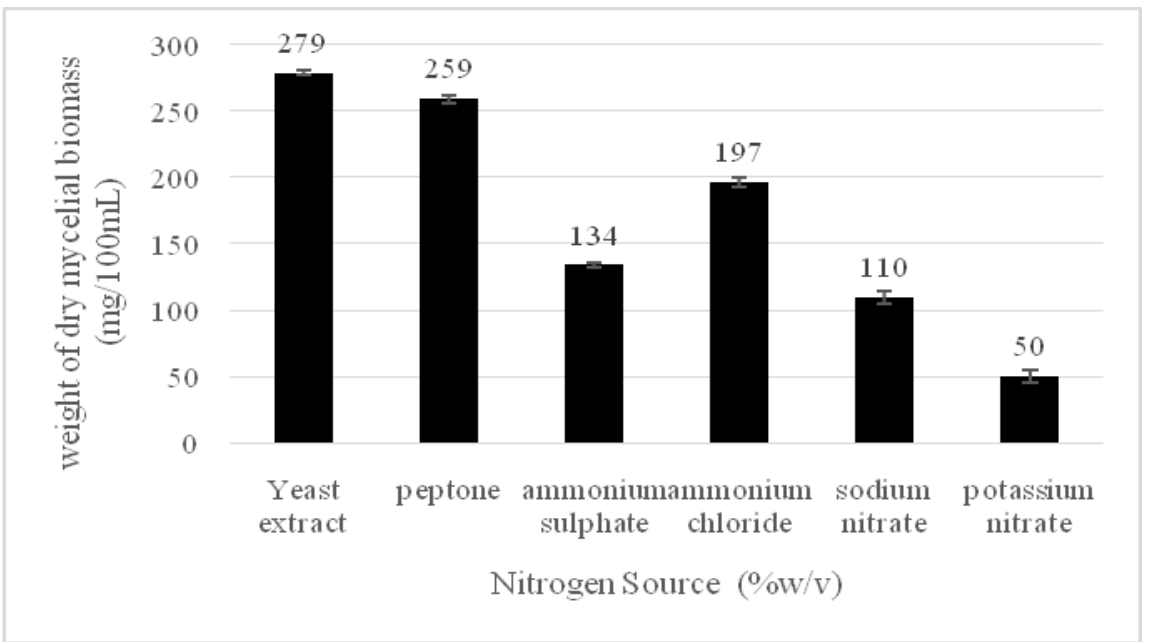

Fig.3 (a)

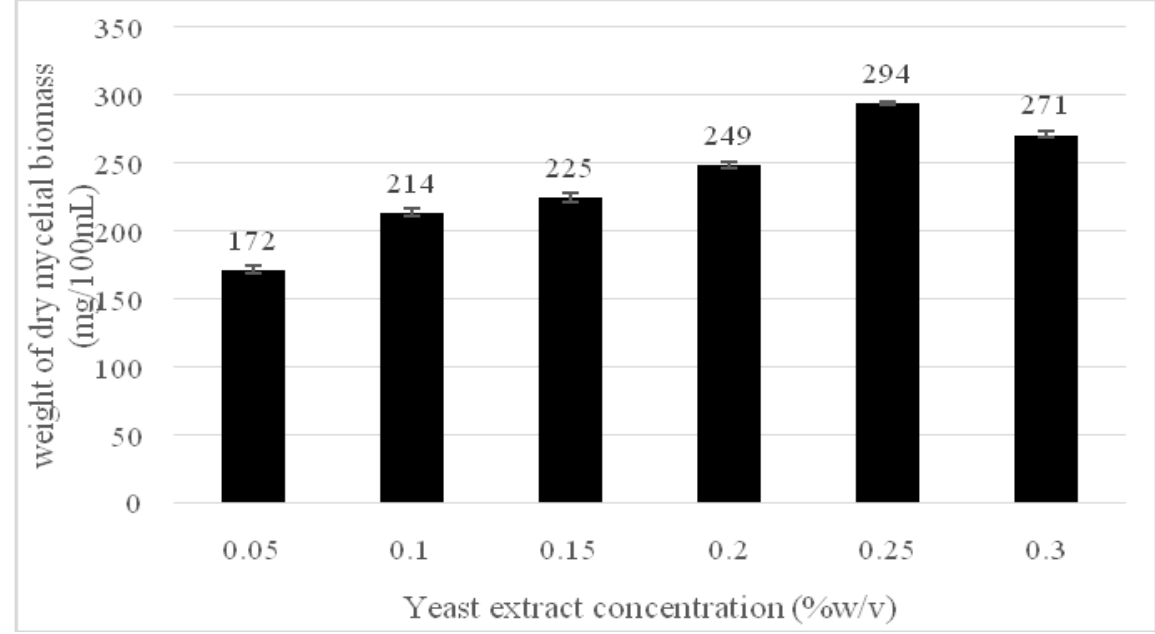

Fig.3 (b) 
Fig.4 Effect of different inoculum sizes on biomass production of G. lucidum. All experimental data are mean \pm S.D. of triplicates

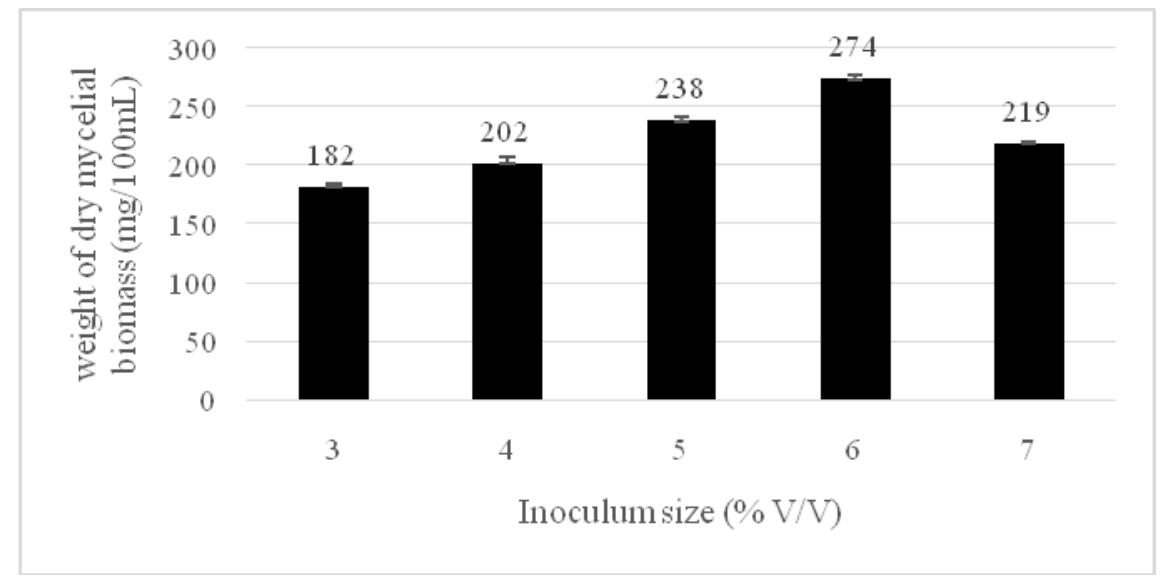

G. frondosa (Lee et al., 2004) was found to grow best at a concentration of $0.8 \% \mathrm{w} / \mathrm{v}$ of yeast extract, which was quite high as compared to the present study.

\section{Effect of inoculum size}

To find the optimum inoculum size, $G$. lucidum was grown under different inoculum volumes ranging from 3-7 \% (v/v). As shown in Figure 4, the optimum inoculum size for production of dry mycelial biomass by $G$. lucidum was found to be $274 \pm 2.49 \mathrm{mg} / 100$ $\mathrm{mL}$ at $6 \%(\mathrm{v} / \mathrm{v})$, whereas moderate mycelial biomass of $238 \pm 3.37 \mathrm{mg} / 100 \mathrm{~mL}$ was observed at inoculum size of $5 \%(\mathrm{v} / \mathrm{v})$. Similar range of inoculum size (2-6\%) was selected by (Lee et al., 2004), to find 3\% (v/v) being the most optimum for the mycelial biomass production of $G$. frondosa. $3 \%(\mathrm{v} / \mathrm{v})$ was also found to be optimum for the growth of Agaricusblazei (Hamedi et al., 2007).

After studying each factor individually in one factor at a time studies, all the factors were combined at their optimum levels obtained and G. lucidum was grown under these conditions. The maximum dry mycelial biomass obtained under these optimal conditions was found to be $368 \pm 3.71 \mathrm{mg} / 100$ $\mathrm{mL}$.

\section{Acknowledgement}

We would like to acknowledge Dr. N.K. Jain, Head, Department of Life Science, Gujarat University, Ahmedabad, for providing us with the necessary facilities needed to conduct our research work.

\section{References}

Chang MY, Tsai GJ and Houng JY. 2006. Optimization of the medium composition for the submerged culture of Ganoderma lucidum by Taguchi array design and steepest ascent method. Enzyme Microb Technol. 38(3-4):407-414.

Fasola TR, Gbolagade JS and Fasidi IO. 2007. Nutritional requirements of Volvariellaspeciosa (Fr. Ex. Fr.) Singer, a Nigerian edible mushroom. Food Chem. 100, 904-908.

Feng YL, Li WQ, Wu XQ, Cheng JW and Ma SY. 2010. Statistical optimization of media for mycelial growth and exopolysaccharide production by Lentinusedodes and a kinetic model study of two growth morphologies. Biochem Eng J. 49, 104-112.

Hamedi A, Vahid H and Ghanati F. 2007. Optimization of the Medium Composition for Production of Mycelial Biomass and Exo-Polysaccharide by Agaricusblazei Murill DPPh 131 Using Response-Surface Methodology. Biotechnology. 6, 456-464. 
Jonathan SG and Fasidi IO. 2003. Studies on Psathyerella atroumbonata (Pegler), a Nigerian edible fungus. Food Chem. 81, 481-484.

Jonathan SG and Fasidi IO.2001. Effect of carbon, nitrogen and mineral sources on growth of Psathyerella atroumbonata (Pegler), a Nigerian edible mushroom. Food Chem. 72(4):479-483.

Lee BC, Bae JT, Pyo HB, Choe TB, Kim SW, Hwang HJ and Yun JW. 2004. Submerged culture conditions for the production of mycelial biomass and exopolysaccharides by the edible Basidiomycete Grifola frondosa. Enzyme Microb Technol. 35, 369-376.

Manjunathan J and Kaviyarasan V.2011. Physicochemical studies on Lentinus tuberregium (fr), a Indian edible fungus. IJPPS. 3(2):60-63.

Papaspyridi LM, Katapodis P, Gonou-Zagou Z, Kapsanaki-Gotsi, E and Christakopoulos P. 2010. Optimization of biomass production with enhanced glucan and dietary fibres content by Pleurotus ostreatus ATHUM 4438 under submerged culture. BiochemEng J. 50(3):131-138.

Shah P and Modi HA.2015. Comparative Study of DPPH, ABTS and FRAP Assays for Determination of Antioxidant Activity. iJRASET. 3(6):636-641.

Sheena N, Lakshmi B and Janardharan KK. 2005. Therapeutic potential of Ganoderma lucidum (Fr.) P. Karst. Natural product Radiance. 4(5): 382-386.

Shih IL, Tsai KL and Hsieh C. 2007. Effects of culture conditions on the mycelial growth and bioactive metabolite production in submerged culture of Cordyceps militaris. Biochem Eng J. 33, 193-201.
Sood G, Sharma S, Kapoor S and Khan PK. 2013. Optimization of extraction and characterization of polysaccharides from medicinal mushroom Ganoderma lucidum using response surface methodology. JMPR. 7(31):2323-2329.

Suberu HA, Lateef AA, Bello IA and Daudu OAY. 2013. Mycelia biomass yield of Ganoderma lucidum mushroom by submerged culture. NJTR. 8(2).

Teoh YP and Don MM. 2012. Optimization of Parameters for Mycelia Growth by Schizophyllum commune and a Kinetic Model Study of its Growth Morphology. Journal of Applied Sciences. 12(11):11001105.

Xiao JH, Chen DX, Wan WH, Hu XJ, Qi Y and Liang ZQ. 2006. Enhanced simultaneous production of mycelia and intracellular polysaccharide in submerged cultivation of Cordyceps jiangxiensis using desirability functions. Process Biochem. 41, 1887-93.

Xu P, Ding Z, Quian Z, Zhao CX andZhang K. 2008. Improved production of mycelial biomass and ganoderic acid by submerged culture of Ganoderma lucidum SB97 using complex media. Enzyme Microb Technol. 42, 325-331.

Yuan B, Chi X and Zhang R. 2012. Optimization of Exopolysaccharides production from a novel strain of Ganoderma lucidum CAU5501 in submerged culture. Braz $\mathbf{J}$ Microbiol. Pp. 490-497.

Zárate-Chaves CA, Romero-Rodríguez CM, Niño-Arias FC, Robles-Camargo J, Linares-Linares M, Rodríguez-Bocanegra MX and Gutiérrez-Rojas I.2013. Optimizing a culture medium for biomass and phenolic compounds production using Ganoderma lucidum. Braz J Microbiol. 44(1):215-223.

\section{How to cite this article:}

Pooja Shah and Modi, H.A. 2018. Optimization of Culture Conditions for Biomass Production of Ganoderma lucidum. Int.J.Curr.Microbiol.App.Sci. 7(02): 1882-1889. doi: https://doi.org/10.20546/ijcmas.2018.702.227 